\title{
ORIGINAL ARTICLE The p53 tetramer shows an induced-fit interaction of the C-terminal domain with the DNA-binding domain
}

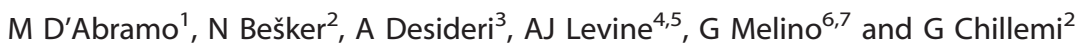

The Trp53 gene is the most frequently mutated gene in all human cancers. Its protein product p53 is a very powerful transcription factor that can activate different biochemical pathways and affect the regulation of metabolism, senescence, DNA damage response, cell cycle and cell death. The understanding of its function at the molecular level could be of pivotal relevance for therapy. Investigation of long-range intra- and interdomain communications in the p53 tetramer-DNA complex was performed by means of an atomistic model that included the tetramerization helices in the C-terminal domain, the DNA-binding domains and a consensus DNA-binding site of 18 base pairs. Nonsymmetric dynamics are illustrated in the four DNA-binding domains, with loop L1 switching from inward to outward conformations with respect to the DNA major groove. Direct intra- and intermonomeric longrange communications between the tetramerization and DNA-binding domains are noted. These long-distance conformational changes link the $C$ terminus with the DNA-binding domain and provide a biophysical rationale for the reported functional regulation of the p53 C-terminal region. A fine characterization of the DNA deformation caused by p53 binding is obtained, with 'static' deformations always present and measured by the slide parameter in the central thymine-adenine base pairs; we also detect 'dynamic' deformations switched on and off by particular p53 tetrameric conformations and measured by the roll and twist parameters in the same base pairs. These different conformations can indeed modulate the electrostatic potential isosurfaces of the whole p53-DNA complex. These results provide a molecular/biophysical understanding of the evident role of the $C$ terminus in post-translational modification that regulates the transcriptional function of $\mathrm{p} 53$. Furthermore, the unstructured $\mathrm{C}$ terminus is able to facilitate contacts between the core DNA-binding domains of the tetramer.

Oncogene (2016) 35, 3272-3281; doi:10.1038/onc.2015.388; published online 19 October 2015

\section{INTRODUCTION}

The Trp53 gene is the most frequently mutated gene in all human cancers. ${ }^{1,2}$ P53 is a powerful transcription factor that is able to activate different biochemical pathways that affect the regulation of cell death ${ }^{3,4}$ and the cell cycle. ${ }^{5}$ The quaternary structure of p53 in its tetrameric form was reconstructed using a combination of NMR, small-angle X-ray scattering, electron microscopy and FRET (fluorescence resonance energy transfer) $^{6-12}$ and showed that an open cross-shaped structure was formed in the absence of DNA, with loosely coupled dimers interacting via the DNA-binding domain (DBD: residues 102-292). In contrast, the structure rigidifies upon DNA binding and becomes more compact. This multitechnique experimental approach showed that the folded core domains interacted with a DNA response element and the tetramerization domains (TETs: residues 323-356) in the Cterminal domain, resulting in conformations that are compatible with those previously described based on experimental data from the separate fragments. All of the remaining portions of the protein (i.e., the linkers connecting DBD with TET, the whole $\mathrm{N}$-terminal domain and the 30 residues at the $\mathrm{C}$ terminus) are intrinsically disordered according to the current structural information.

There is an absence of information on the additional components of the transcription machinery; therefore, a molecular dynamics (MD) investigation could allow an incremental advance in understanding the possible intermolecular interaction at the tetramer level.

We previously described the MD of the full-length p53 monomer, ${ }^{13}$ which showed a very stable structure for up to $850 \mathrm{~ns}$ in the DBD but significant flexibility both in the N-terminal transactivation domains (TAD1 and TAD2) and the C-terminal region, including the tetramerization domain. This flexibility disclosed several hydrogen bonds between the $\mathrm{N}$ and $\mathrm{C}$ termini or between them and the DBD. Clearly, these interactions may change in the tetramer, and therefore we have undertaken a subsequent investigation herein to analyse the interactions at the level of the p53 tetramer.

As noted by Lubin et al., ${ }^{14}$ destabilizing mutations cause the DBD to misfold only when it is part of the tetramer, but not when it is in its monomeric state. The building of an atomic model and its conformational sampling by state-of-the-art MD simulations can furnish structural information not obtainable by any experimental technique and help unravel the biological mechanism of p53 oncogenic mutants. In silico experiments on truncated forms of p53 have already proven their usefulness. ${ }^{15-17}$

\section{RESULTS}

We built a detailed atomistic model for residues 92-360 of p53 in its tetrameric form and in interaction with a consensus

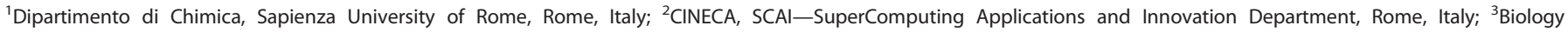

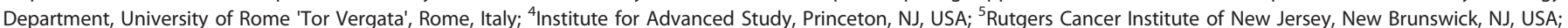

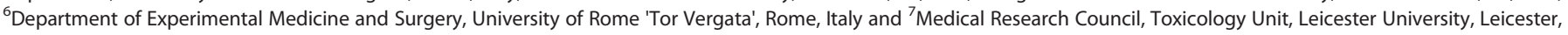
UK. Correspondence: Dr G Chillemi, CINECA, SCAI-SuperComputing Applications and Innovation Department, Via dei Tizii, 6, Rome 00185, Italy. 
a

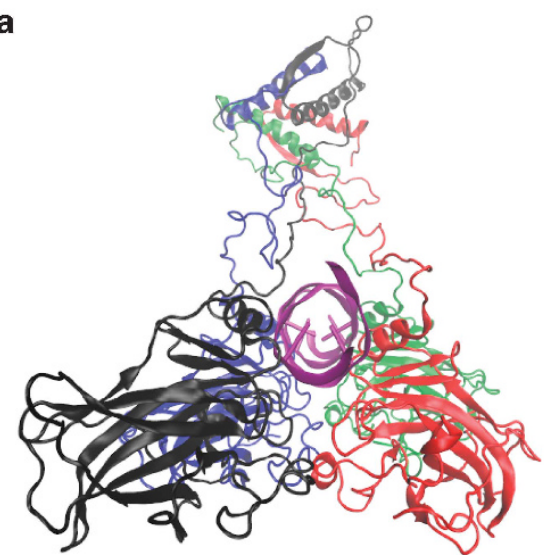

b

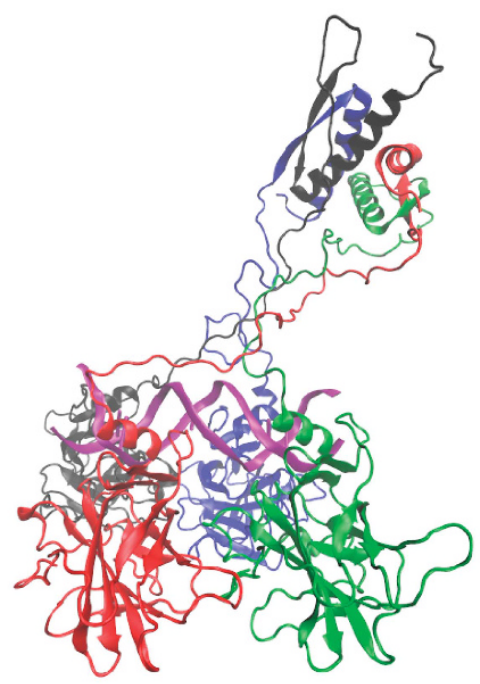

C

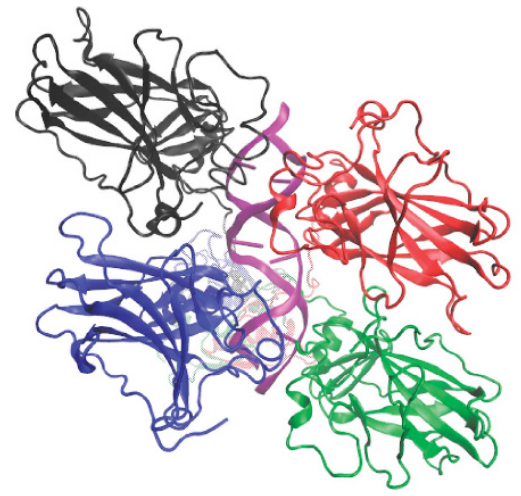

e
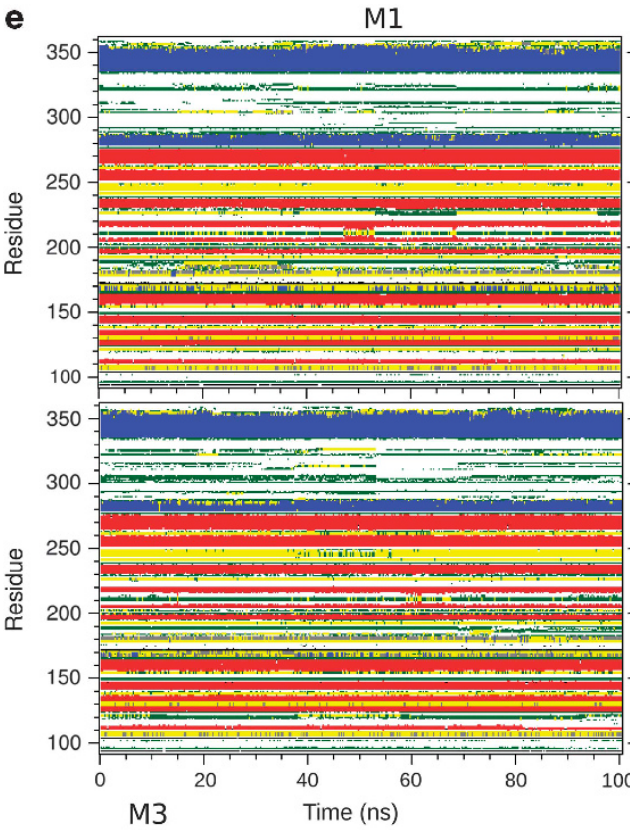

d

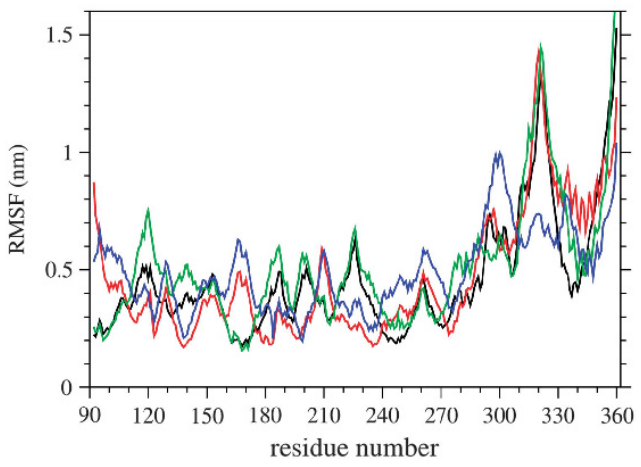

M2

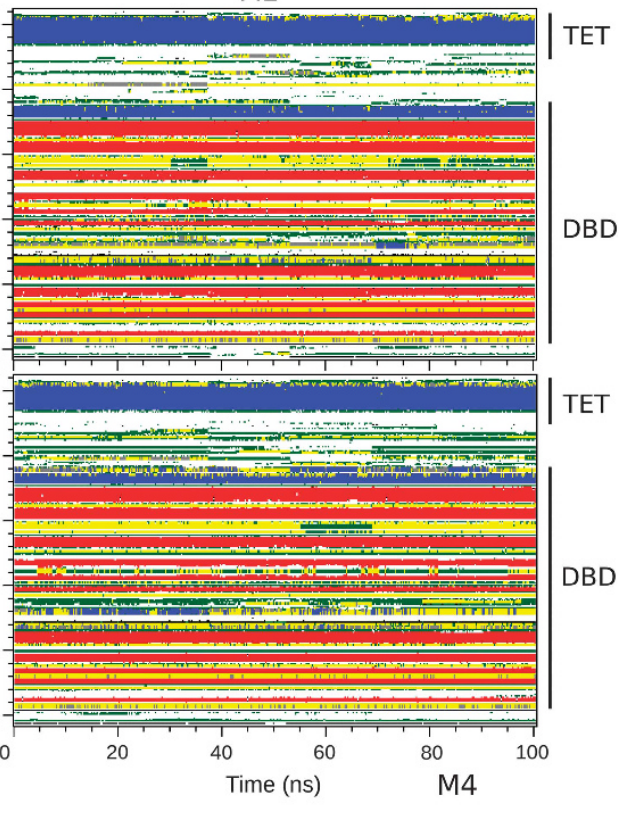

$\square$ Coil $\square$ B-Sheet

B-Bridge

Bend $\square$ Turn

A-Helix $\square$ 3-Helix

Figure 1. (a-c) The 3D structure model of p53 is shown here in its tetramer form bound to a full DNA consensus site extracted from the MD simulation. The four monomers are coloured in black, red, green and blue. The 18 bp DNA structure is coloured in purple. (d) Per-residue rootmean-square fluctuations (RMSFs) for each p53 monomer (colours as in a-c). Arrows highlight the residues belonging to the DBD, the tetramerization domain (TET) and the tetramerization helix (TE). As previously described for full-length p53, ${ }^{13}$ the DBD region is significantly more rigid, with relatively low RMSF values. (e) Secondary structure as a function of simulation time. The four monomers (M1-M4) show a very stable structure over time in the DBD and TE, whereas specific regions are able to switch between $\alpha$-helix (blue), turn (yellow) and bend (green). 
DNA-binding site that was 18 base pairs in length (Figures 1a-c). To the best of our knowledge, this is the only model of p53 in its tetramer form that includes the tetramerization helices and $\mathrm{Zn}$-binding ions. Our previous study of full-length p53 showed a key role for the $\mathrm{Zn}$-coordinated helix $\mathrm{H} 1$ at the centre of the long-range interactions with: (1) the N-terminal domain through His178; (2) the REG region (residues 363-393) in the C-terminal domain through His179; and the $\beta$-sandwich and the loop-sheethelix regions in DBD through the $\mathrm{Zn}$-coordinated cysteine residues. $^{13}$ In this work, we focus our attention on these last interactions in the p53-DNA complex.

\section{Structural stability of the p53 tetramer}

After an initial equilibration where weak restraints were applied to the DNA and tetramerization helices, four independent all-atom MD simulations were performed that totalled $100 \mathrm{~ns}$. The structure and dynamics of the tetramer are characterized for three different regions: DBDs, TETs and the loop connecting them (residues 293-322). As expected, the per-residue root-mean-square fluctuation shows that the loops are the more flexible regions of the protein complex (Figure 1d), whereas the DBDs and TETs remain quite rigid. Moreover, inspection of their secondary structure contents along the trajectories (Figure 1e) confirms this behaviour. Per-residue root-mean-square fluctuation and secondary structure analysis indicate that while the overall structure is well conserved in the four monomers, subtle dynamic differences are observed, particularly in monomer 4 (M4) compared with the others. For example, the region of maximum flexibility in this monomer is not located around residues $312-330$ as it is for the other monomers but in residues 295-305. Both of these intervals are located at the $\mathrm{N}$ termini of the TEs (tetramerization helices; residues 335-355). Moreover, an a-helix propensity for residues $175-180$ is shown by M4 alone during the 100 ns timeframe (Figure 1e). Note that two of the four $\mathrm{Zn}$-binding residues are present in these ranges (i.e., Cys176 in loop 2 and His179 in the $\mathrm{H} 1$ helix) (Supplementary Figure S1).

\section{Long-range interdomain communications}

Owing to the subtle thermodynamic regulation of the p53 tetramer that has also been associated with a mechanism that is able to prevent cancer-induced misfolding in p53 oncogenic mutants, ${ }^{14}$ we investigated long-range coupling dynamics to highlight how the domains were (dynamically) coupled and describe the key regions characterizing the overall tetramer motion. To extract these biologically relevant motions, we calculated the Dynamic Cross Correlation (DCC) $\mathrm{Map}^{18}$ and performed Essential Dynamic (ED) analyses. ${ }^{19}$

The DCC Map for the p53 tetramer is shown in Figure 2a. This analysis furnishes an overall picture of the correlated motions that occur between protein residues during the simulation. Highly positive peaks of the elements of the map (Cij) are indicative of a strong correlation between the movement of residues $i$ and $j$, whereas negative $\mathrm{Cij}$ values denote that the two residues move in opposite directions (anticorrelated motion). Both cases are relevant when investigating biological macromolecules, particularly in couples of residues that are located far apart in the three-dimensional (3D) structure. Long-range correlated movements are often linked to the biological functions of the protein. ${ }^{20-23}$ The analysis was performed on the $1076 \mathrm{C}$-a carbons of the tetramer (269 for each monomer) because they contain sufficient information to describe the largest protein motions. Note that the map is symmetrical, so the choice of highlighting a particular element in the upper left or lower right is only because of visual effects. The four squares along the black diagonal (each residue has a correlation of 1 with itself) contain the movement correlation among the residues of each monomer. The figure clearly shows highly correlated movements among the
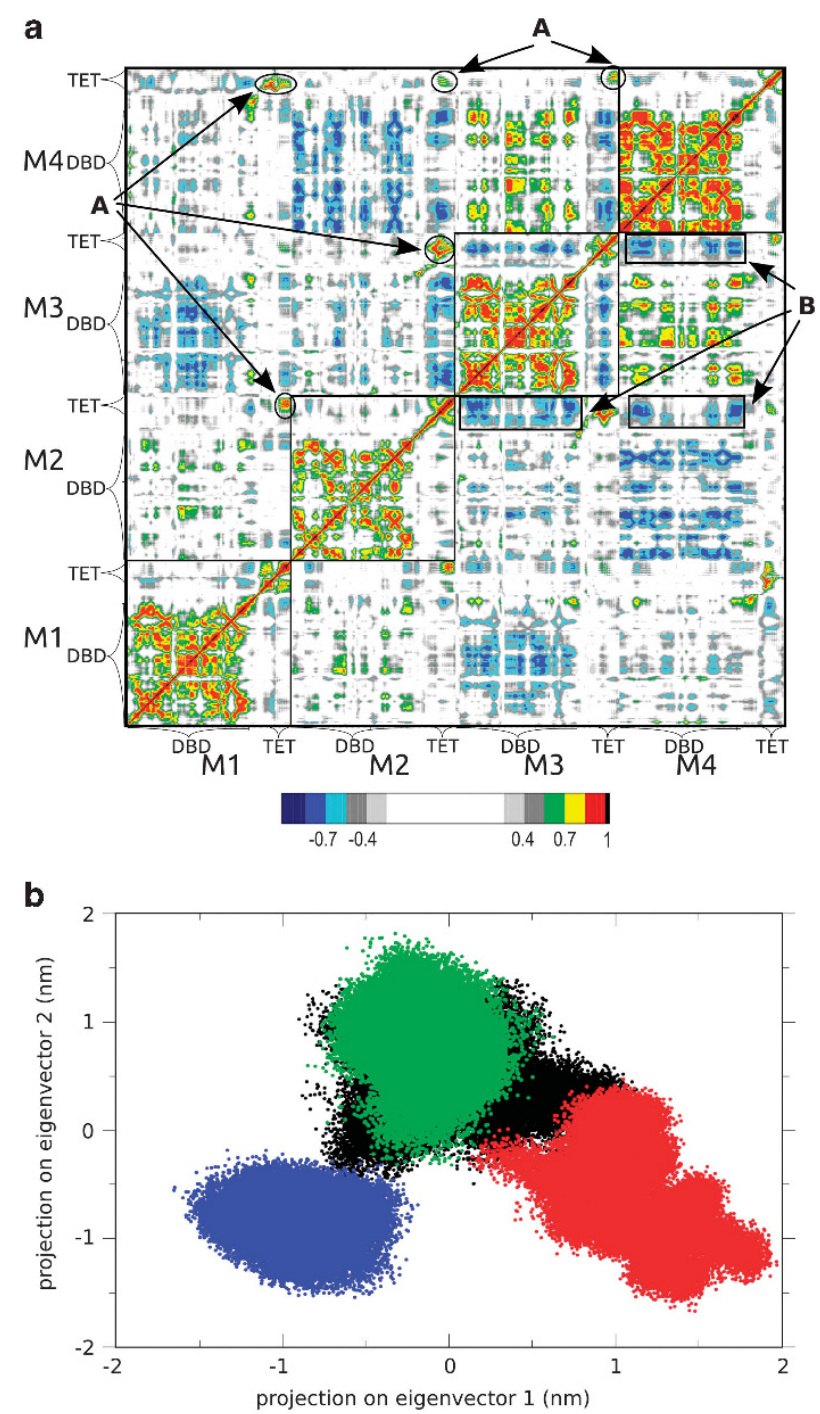

Figure 2. (a) DCC Map for the p53 tetramer. Four squares delimit the intra-DBD interactions in monomers M1-M4. High correlated motions between couples of TET are highlighted by ellipses A. High anticorrelated motions between TET-DBD couples are highlighted by rectangles $\mathrm{B}$. (b) $2 \mathrm{D}$ projection of the concatenated $\mathrm{DBD}$ trajectory on the essential subspace along eigenvectors 1 and 2 . The structural basin visited by the different monomers is highlighted in different colours (M1-M4 colours as in Figures 1a-d).

DBD residues in all monomers with differences in intensity (the DBD in M4 shows the highest correlation among its residues). In contrast, only $\mathrm{M} 3$ shows a strong anticorrelation between the $\mathrm{DBD}$ and TET residues. Regarding the intermonomer correlations in DBD, M2 and M4 exhibit the highest (anti)correlation, whereas M1 and M3 have a similar but lower signal. A positive correlation is observed between the DBDs in M3 and M4. No significant correlations are observed between the DBDs in the couples $\mathrm{M} 1-\mathrm{M} 2, \mathrm{M} 1-\mathrm{M} 3$ and $\mathrm{M} 2-\mathrm{M} 3$.

Positive correlations are present between nearly all of the TET couples (highlighted by ellipses in A). Interestingly, we observe the presence of a strong anticorrelation signal between the TET in M2 and DBD in M3 and M4 and between the TET in M3 and DBD in M4 (highlighted by the three rectangles in B). These last interactions, together with the strong anticorrelation between DBD and TET in M3, demonstrate that the role of TETs in the tetramer is not over after the formation of the complex with DNA. Instead, communication between TETs and DBDs is always 
a
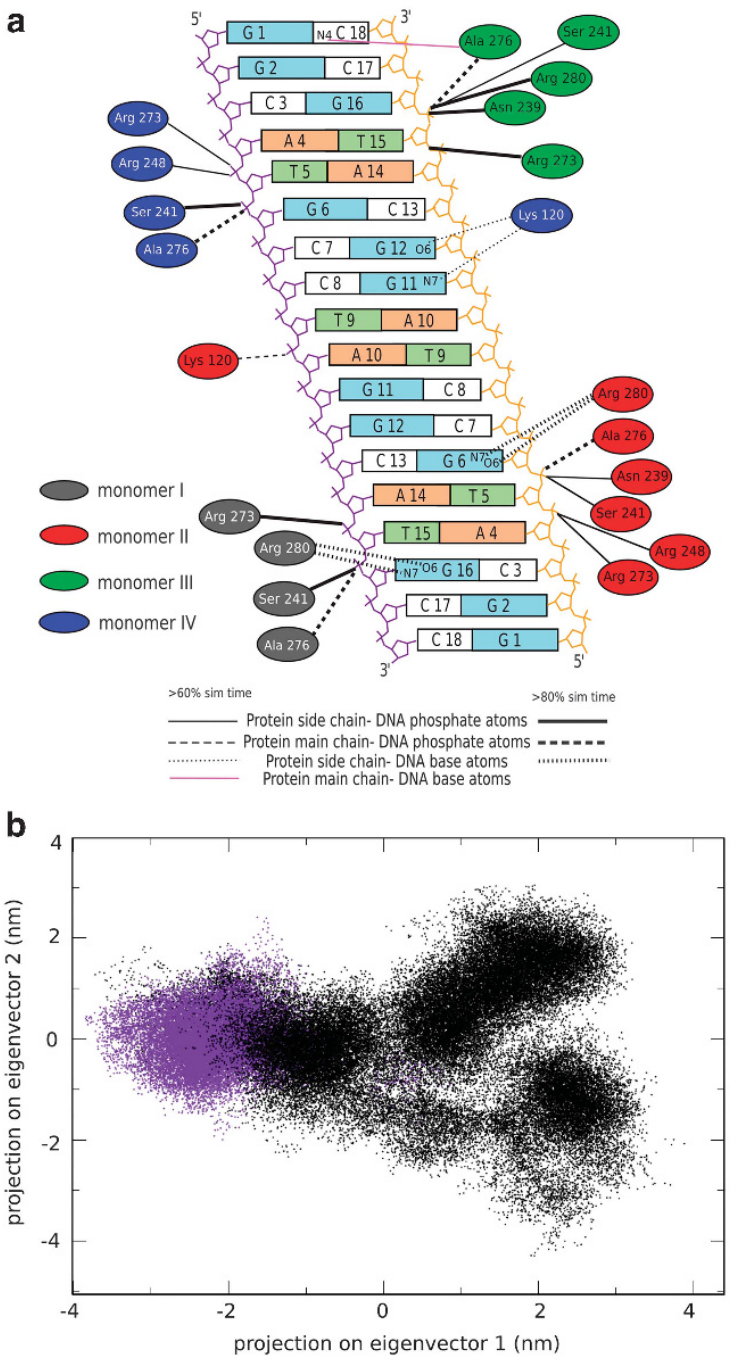

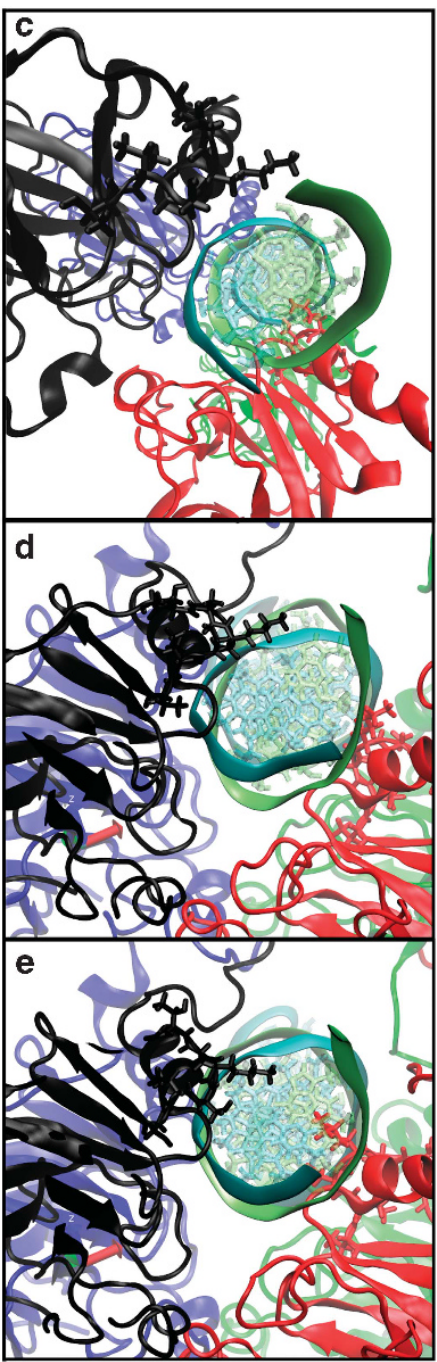

Figure 3. (a) Direct protein-DNA interactions in the p53 tetramer. (b) $2 \mathrm{D}$ projection of the DBD trajectory in the p53 tetramer on the essential subspace along eigenvectors 1 and 2. The conformations in which both the DNA roll and twist parameters for the central TA bases are significantly different from their corresponding values found in standard B-DNA are shown in purple. The essential subspace in which the DNA is distorted is separated along the first eigenvector from the great majority of the p53 tetramer conformations visited during the simulation. (c-e) 3D snapshots of L1 in M1 and M2 (black and red colours, respectively). (c) In the X-ray structure (PDB 3KMD) L1 adopts an outward projection away from the DNA major groove in M1, whereas the same loop tucks into the major groove in M2. (d and e) During the MD simulation, L1 in M1 is observed to move from the outward (d) to an inner conformation (e) with respect to the major groove that is visited for nearly the $40 \%$ of the simulation time. In contrast, L1 in M2 maintains the inner conformation of the starting X-ray for nearly $60 \%$ of the simulation time (e), but the outward conformation is sampled as well (d).

maintained in the p53 tetramer. This is consistent with the hypothesis that the DBD can hop on/off the DNA to search for responsive elements. ${ }^{24}$ Moreover, structural communications between TETs and DBDs are likely to occur during the p53-DNA dissociation step. The analysis of the DCC Map clearly highlights the significant asymmetry of the monomers, with $\mathrm{M} 3$ at the centre of nearly all of the primary long-range correlations between the p53 tetramer elements.

\section{Asymmetric motion of the four DBDs}

We investigated the structural basin generated by the four DBDs by concatenating their trajectories and then performing an ED analysis on the obtained $100 \times 4$ ns long sampling. Root-meansquare fluctuations of the $\mathrm{C}-\mathrm{a}$ atoms along the first two ED eigenvectors (Supplementary Figure S2) indicate that their principal motions are dominated by the fluctuations of the two segments connecting the $\beta$ - strands as in Supplementary Figures S6 and S7 (residues 208-213; see Supplementary Figure S1 for secondary structure nomenclature of the DBD) and Supplementary Figures S6 and S8 (residues 220-229) located in regions opposite the DNA and exposed to the solvent (Supplementary Figure S2). Moreover, the different motion of loop L1 (residues 117-122) in the four monomers is well captured by the second eigenvector. This dynamic information is further discussed in the context of protein-DNA interactions.

The projection of the concatenated DBD trajectory on the essential subspace defined by the first two eigenvectors (Figure 2b) shows a similar conformational behaviour for the M1 and $\mathrm{M} 3$ monomers that sample the same subspace region. In contrast, the M2 and M4 monomers visit different regions, thereby reflecting differences in the conformations sampled along eigenvectors 1 and 2. This analysis also indicates that the second eigenvector is able to discriminate between the two couples of monomers (i.e., M1-M3 vs M2-M4), implying that protein regions that are significantly active in this eigenvector (e.g., loop L1) are likely to have a key role in determining the similarities (M1-M3) 
Table 1. Local base-pair step parameters for the average MD and starting X-ray structure (Chen et al. ${ }^{25}$ )

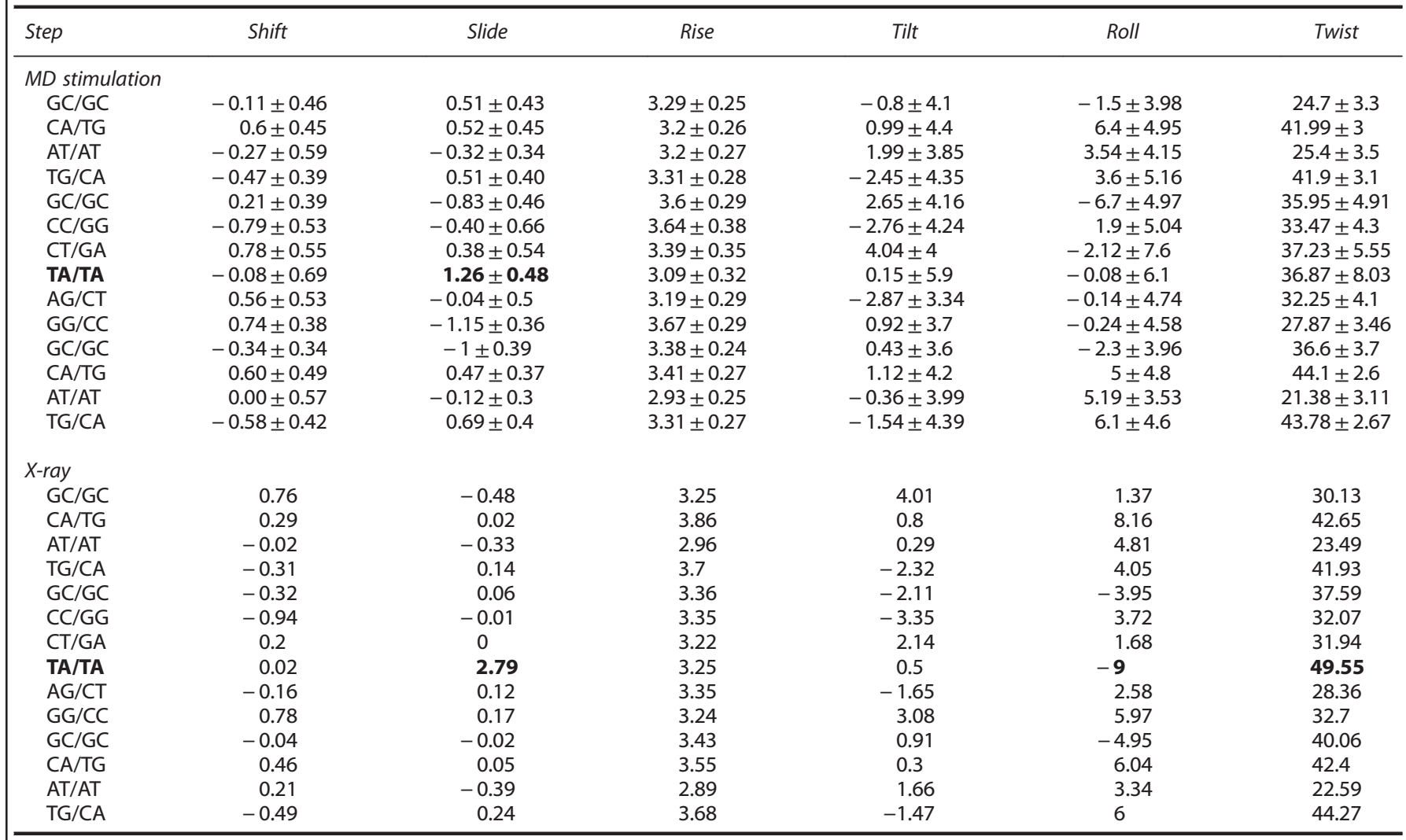

Abbreviation: MD, molecular dynamics. Only the central TA bases show a deviation from B-DNA. The DNA parameters that are significantly different from their corresponding values found in standard B-DNA are shown in bold.

and differences (M1-M3 vs M2 vs M4) in monomer conformational behaviour. In accordance with the DCC map (Figure 2a), a break in the tetramer symmetry in the DBDs is observed.

\section{P53-DNA interactions}

The high correlations between key p53 regions demonstrate the presence of structural and dynamic long-range communications in which DBD is central. We investigated its role in the interaction with DNA by identifying the long-lasting (longer than 60 or $80 \%$ of the simulation time) direct hydrogen bonds between $\mathrm{p} 53$ and the 18 bp DNA (Figure 3a). In accordance with the X-ray data, ${ }^{25}$ all monomers strongly interact with the phosphate backbone of T5-G6 or T15-G16. Some contacts are well conserved in all of the monomers, such as the interaction between Arg273 with T15 in $\mathrm{M} 1$ and $\mathrm{M} 3$ and with $\mathrm{T} 5$ in $\mathrm{M} 2$ and $\mathrm{M} 4$ or the interaction between Ala276 and Ser241 with G16 in M1 and M3 and G6 in M2 and M4. Other interactions are present only in some monomers, such as that between Arg248 and T5 in M2 and M4 and Asn239 with G6 and $\mathrm{G} 16$ in $\mathrm{M} 2$ and $\mathrm{M} 3$, respectively.

In addition to these nonspecific DNA-protein interactions, some base-specific interactions are also present. Arg280 in helix $\mathrm{H} 2$ forms very stable contacts with G16 in M1 or G6 in M2. Notably, M3 and M4 also participate in these latter interactions but for a percentage of time that is shorter than the chosen $60 \%$ threshold (compare $>85 \%$ of the simulation time in $\mathrm{M} 1$ and $\mathrm{M} 2$ vs $36-55 \%$ in M3 and M4). Ala276 in M3 contacts N4 of G18. The very stable base-specific interactions between Lys 120 and the G11-G12 bases in M4 (63 and 65\%, respectively) are also present in M2 with a permanence time of $44-57 \%$ and $M 1$ with a permanence time of $36-39 \%$. M2 also possesses a very stable interaction of Lys 120 with the A10 backbone atoms. Interestingly, the X-ray study of the p53 tetramer highlighted two distinct conformations for the loop L1 (residues 117-122) in M2 and M4 in which L1 tucked into the major groove, in contrast with $\mathrm{M} 1$ and $\mathrm{M} 3$ where L1 adopted an outward projection away from the major groove. In our $100 \mathrm{~ns}$ simulation, analysis of the direct Lys120-DNA interactions shows that while L1 in M4 maintains an interaction with DNA for nearly the entire simulation time, these are weaker in M2; moreover, M3 maintains the outward conformation for the entire simulation time, and we observe a change in the orientation of $L 1$ in $M 1$ that allows the formation of base-specific interactions for nearly $40 \%$ of the simulation time.

Therefore, observation of the hydrogen bond network formed by Lys 120 in the four DBDs can increase our understanding of the dynamic behaviour of loop L1, which is captured by the second eigenvector in the previously described DBD ED analysis. Examining the conformational space visited by the four monomers along this principal motion direction, we observe that M4 visits a smaller space (blue area in Figure $2 \mathrm{~b}$ ), which is in accordance with the observed persistence of the loop L1-DNA contact. M3 (green area in Figure 2b), which does not show a relevant interaction with DNA, visits a conformational region far from the M4 region. The conformational regions visited by M1 (black area in Figure 2b) and M2 (red area in Figure 2b) along the second eigenvector largely overlapped with those of $M 2$ and $M 3$, respectively. This again is in accordance with their initial loop L1 conformations captured by X-ray. However, in contrast with the other two monomers during the simulation, $M 1$ and $M 2$ visit conformations that are different from the starting conformations (which again is in accordance with the relatively larger and overlapping essential subspace visited by these monomers). The $3 \mathrm{D}$ conformations of $\mathrm{L} 1$ in the starting $\mathrm{X}$-ray conformation and in 


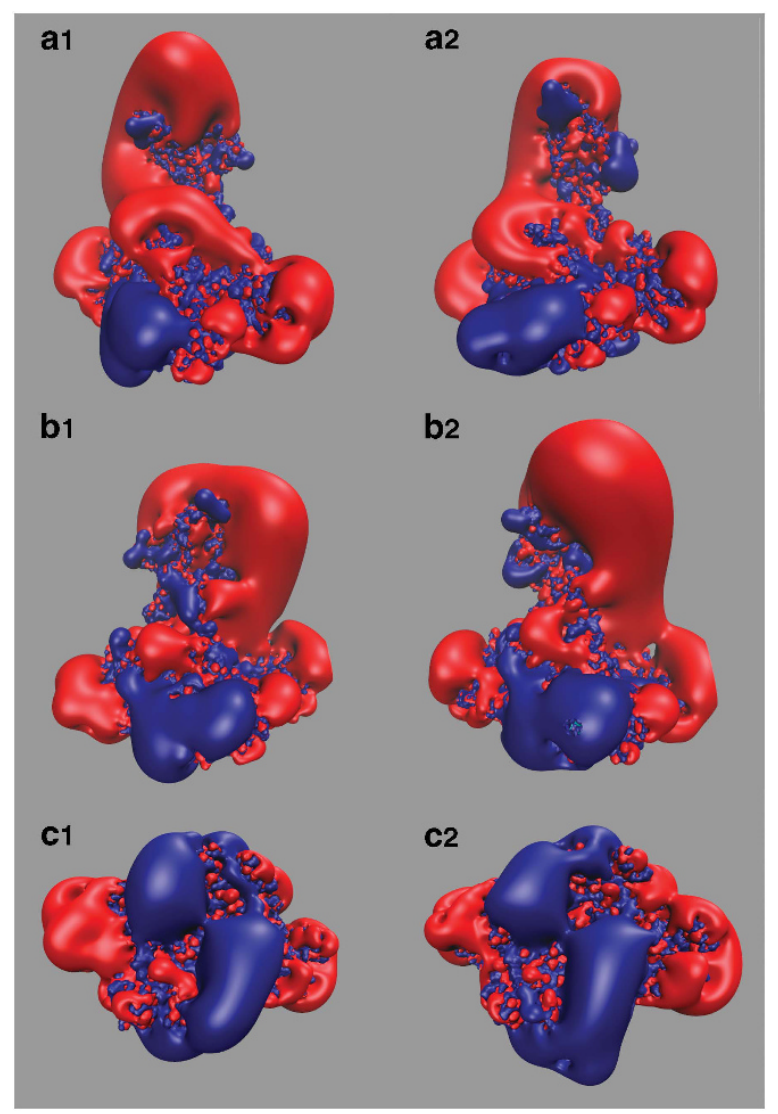

Figure 4. Positive and negative electrostatic potential isosurfaces at a contour level of $\pm 1 \mathrm{KT} / \mathrm{e}$ are depicted in red and blue colours, respectively. (a1-c1) Different orientations of the conformation corresponding to the minimum of the first eigenvector of the DBD tetramer ED (Figure 3b). (a2-c2) Same orientations as panels a1-c1 for the conformation corresponding to the maximum of the first eigenvector of the DBD tetramer ED (Figure $3 \mathrm{~b}$ ).

two representative MD snapshots are shown in Figures 3c-e. In our MD simulation, L1 in M1 is observed to move from the outward (Figure 3d) to an inner conformation (Figure 3e) with respect to the major groove. In contrast, L1 in M2 maintains the inner conformation of the starting X-ray for nearly $60 \%$ of the simulation time (Figure 3e), although the outward conformation is sampled as well (Figure 3d).

It is worth noting that loop L1 has been proposed to regulate p53-DNA-binding kinetics and to confer sequence specificity. ${ }^{26}$ Moreover, a computational simulation of the DBD tetramer performed by Pan and Nussinov ${ }^{27}$ before the availability of the $\mathrm{X}$-ray structure used in our model (and therefore with different p53 starting positions and a different DNA sequence), nevertheless, suggested a key role for Lys 120 in loop L1 as an allosteric switch for the p53-DNA tetrameric interaction.

\section{DNA structure and protein-coupled motions}

From the analysis of the DNA parameters ${ }^{28}$ obtained by our MD simulations, we found that DNA remained largely in its B-form, ${ }^{29}$ although we observed a slight distortion of the slide parameter of the central thymine-adenine base pairs that was in accordance with the crystallographic data. ${ }^{25}$ Table 1 shows the average DNA parameters from our MD in comparison with those observed in the initial X-ray structure.

The X-ray starting structure has a significant deviation in the central TA bases from the standard B-DNA in three parameters: slide, roll and twist (bold in Table 1). The slide parameter for the same couple of bases shows an analogous deviation to that observed in the X-ray structure during the entire simulation time. In contrast, a deviation from the standard B-DNA of the roll and twist parameters is only observed in a region of the conformational space sampled during the MD simulation. The projection of the trajectory along the first and second eigenvectors obtained from the essential dynamic analysis of the whole p53 core in its tetrameric form is shown in Figure $3 \mathrm{~b}$. We coloured the tetramer conformations in which the DNA roll and twist parameters deviate from the B-DNA in purple. Interestingly, this DNA distortion coincides with a well-defined area of the tetramer essential subspace, thereby demonstrating a clear coupling between the DNA distortion and p53 core tetramer conformations.

Therefore, our MD simulation was able to differentiate between slide distortion that is most likely due to the binding of the p53 tetramer itself and the other DNA distortion measured by the roll and twist parameters that is dynamically switched on and off as a function of the specific p53 tetramer conformation and is instantaneously visited. The ED analysis shows that this last DNA distortion is observed only when a specific region (well described by the first eigenvector) of the tetramer conformational space is visited.

Induced-fit effect in p53: how the $\mathrm{C}$ terminus facilitates contact with the core DBDs of p53

Recently, the unstructured lysine-rich region in the p53 C-terminal domain was shown to control site-specific DNA binding and to promote structural changes in the DBD. ${ }^{30}$ The findings reported in the present study provide a biophysical explanation for the biological evidence demonstrated by Laptenko et al. ${ }^{30}$ Collectively, both studies represent an important step towards discrimination between two non-mutually-exclusive alternatives that contribute to the regulation of specific p53-DNA complexes via the C-terminal domain. In the first scenario, the C-terminal domain provides multiple nonspecific p53-DNA interactions that stabilize the binary complex (i.e., the lysine residues function simply as an anchor set on each side of the corresponding binding site to provide extra stabilization). The second possibility is based on an induced-fit mechanism, ${ }^{26,31}$ where the C-terminal domain actually induces specific local conformational changes within the p53 tetramer upon binding to the p53 site.

In our model, the unstructured fragment containing Lys370, $372,373,381,382$ and 386 is not present (see the Materials and methods section); hence, this structure corresponds to the experimental $\Delta 30 \mathrm{p} 53$ form. ${ }^{30}$ Our results clearly demonstrate long-range effects of TET on the conformations visited by DBD, further producing a deformation in the bound DNA structure. Therefore, our data demonstrate the existence of an induced-fit mechanism that is in keeping with the experimental results obtained with $\Delta 30 \mathrm{p} 53$, which demonstrated that in the absence of the lysine fragment the effect is eventually modulated.

To further understand this complex biological interaction, we investigated the mechanism by which p53 may transduce local DBD conformations. Specifically, we investigated the long-range effects of Lys120 that are capable of influencing or being influenced by other molecular partners. To this end, we calculated the electrostatic potential of two p53-DNA tetramer conformations that were representative of different structural basins. These conformations were chosen at the extremes of the first eigenvector of the DBD tetramer essential dynamics (purple point at the left and black point at the right in Figure 3b). The distribution of the positive and negative isosurfaces at a contour level of $\pm 1 \mathrm{KT} / \mathrm{e}$ is depicted in Figure 4 and Supplementary Figures S3-S9 for different orientations of the two structures. The tetramer has a dominant-negative surface in the TET region (Figures $4 a$ and $b$, red colour) and a dominant-positive surface in the central DBD 
region that almost completely covers the negatively charged DNA. However, a negative surface (Figure $4 c$ ) is shown in correspondence of $\beta$-strands S1 and S3 and loop 2, connecting $\beta$-strands S3-S4 and S7-S8 (see Supplementary Figure 2S). Therefore, the complex is fully able to modulate the electrostatic surface according to the two different conformations (compare Figure 4, panels 1 vs 2). For example, when the tetramer visits the structural basins at a minimum value along the first essential eigenvector (panels 1), the negative isosurface in contact with TET completely changes its orientation and volume (compare $A 1$ vs $A 2$ and $B 1$ vs $B 2$ ). This is the biophysical rational for the induced-fit interaction between the $C$ terminus and the DBD.

\section{DISCUSSION}

P53 was originally named the guardian of the genome and was thought to protect the organism from cancer, infertility and ageing $^{32-45}$ (reviewed in refs 46-49). The most significant evidence involving p53 in cancer is its high mutation rate in cancers and its ability to drive cancer progression when mutated. ${ }^{50-56}$ At the metabolic level, p53 affects mitochondrial function, resulting in activities that directly regulate the survival of the cell. ${ }^{57-63}$ The understanding of the highly complex signalling regulation of $\mathrm{p} 53^{64-70}$ has been further complicated by the presence of different protein isoforms. ${ }^{71-74}$ P53 and its family members exert their actions by regulating the cellular microRNA in an intricate network. ${ }^{75-84}$ Additionally, there is also a rather complex interaction between p53 and autophagy that acts in both directions. ${ }^{85-89}$ Several novel drug design or high content screening investigations are attempting to use the p53 pathway for therapeutic applications in cancer, ${ }^{90-95}$ mostly by exploiting its protein stability ${ }^{96-99}$ rather than its transcriptional activity. ${ }^{100-104}$ Recently, p53 aggregation studies indicated an important regulatory effect of the conformation for the p53 protein. ${ }^{105-107}$ Consequently, we propose that an atomistic model of the p53 tetramer including the C-terminal tetramerization helices can improve our understanding of this system.

The MD simulation of the p53 tetramer in complex with DNA highlights the presence of long-range communication between different domains that allows $\mathrm{p} 53^{\prime} \mathrm{s}$ biological function. The inclusion of the TET at the p53 C terminus for the first time in an atomistic model permits the observation of long-range communications both at the intramonomer level between TET and the whole DBD in M3 (Figure 2a) and at the intermonomer level between M2-TET and M3-DBD and between M3-TET and M4-DBD (Figure 2a). The protein displays a double-face interaction with DNA through several nonspecific non-covalent bonds with the DNA backbone (mostly accomplished by $\beta$-strands S9 in the $\beta$-sandwich and the $C$-terminal end of $\beta$-strand S10 in the loopsheet-helix motif), whereas specific sequence recognition is performed by helix $\mathrm{H} 2$ and loop L1, both located in the loopsheet-helix motif (Figure 3a). Loop L1 shows nonsymmetric dynamics in the four monomers, as evidenced by the essential dynamics of the concatenated DBD trajectory along the second eigenvector (Figure $3 \mathrm{~b}$ and Supplementary Figure S2). The simulation shows the switch from a conformation in which L1 tucks into the major groove to an outward projection away from the major groove, and vice versa (Figures $3 c-e$ ). These results provide an atomistic explanation for the regulation of p53 functions through post-translational modifications of the $C$ terminus. ${ }^{108,109}$

The $C$ terminus of $p 53$ has a strong biological effect on the transcriptional function of p53 itself because it is able to regulate DNA binding, p53 stability, p53 subcellular localization and the recruitment of cofactors (see Laptenko et al. $^{30}$ ). Although this effect has been related to changes in the affinity of electrostatic interactions between the lysines at the $C$ terminus during specific binding with other $\mathrm{p} 53$ regions, the in-depth mechanism has not been clarified. Although our manuscript was in evaluation, Laptenko et al. $^{30}$ demonstrated the biological value of the lysine interaction on the stability of the p53-DNA complex through the facilitation of cooperative contacts with the DBD. ${ }^{30}$ This result can be explained by the pivotal concept of the 'induced-fit theory'. Indeed, Petty et al. ${ }^{26}$ showed a conformational change within the DBD that involved the L1 loop, which adopted either an extended or a recessive conformation. Our data show the dynamic flexible movement of the four monomers and demonstrate how the $C$ terminus can modulate the electrostatic surface regardless of the presence of the lysines (which are absent in our model) (Figure 4) according to the two different conformations at the extreme of the first essential eigenvector. This is the biophysical rational for the understanding of the C-terminus interaction with the DBD.

The implications of our results are evident on the induced-fit theory (see Koshland ${ }^{110}$ and Johnson ${ }^{111}$ ) and fully explain the results by Laptenko et al. ${ }^{30}$ The presence of an induced-fit conformational transition will change the kinetic equilibrium, where multiple structural switches allow a better fit between p53 and DNA, thereby stabilizing the bound conformation. Halazonetis identified a role for L1 in this mechanism, ${ }^{112}$ although we cannot exclude conformational induced fit by other association partners taking place in the transcription machinery complex. ${ }^{113}$ As indicated above, our results in keeping with Laptenko et al. ${ }^{30}$ demonstrate that the $C$ terminus can create an induced-fit mechanism per se on the DBD, even in the absence of other partners. Note that long-range interdomain communications have been already highlighted in the p53 full-length model ${ }^{13}$ and preliminary results on cancer-related mutations located in DBD confirm the ability of p53 to deeply alter the dynamics of the TAD regions in the $\mathrm{N}$-terminal domain and TET in the $\mathrm{C}$-terminal domain (Figure 5).

Concerning the DNA conformation, a general standard B-form is maintained in the entire double strand; the only exception is the central thymine-adenine base pairs (Table 1). This result was in agreement with the description of the 3D structure obtained by $X$-ray diffraction. However, the simulation implies that the slide parameter is outside the range of the standard B-form for the entire simulation time, whereas the roll and twist parameters (also distorted in the starting X-ray structure) are distorted in the MD simulation only for tetrameric conformations corresponding to a specific region of the essential subspace (purple points in Figure 3b). Therefore, the MD simulation separates the 'static' DNA deformation that most likely occurs because of p53-DNA binding (measured by the slide parameter) from the 'dynamic' DNA deformation (measured by the roll and twist parameters) that is switched on and off as a function of the specific p53 tetramer conformation.

\section{MATERIALS AND METHODS}

The model of the p53 tetramer in interaction with a specific DNA response element was built using the Modeller software package ${ }^{114}$ with the X-ray crystal structure 3KMD as a reference for the p53 core domains and DNA. ${ }^{25}$ The NMR structures from 3SAK were used as references for the tetramerization helices. ${ }^{115}$ The first 90 residues at the $\mathrm{N}$ terminus and residues $360-391$ at the $C$ terminus are intrinsically disordered. ${ }^{13}$ We have excluded them from the model for two main reasons: (i) the inclusion of these residues in the model makes the system computationally very demanding and (ii) they would not affect the conformational behaviour of the rest of the protein complex. Forcefield parameters for the $\mathrm{Zn}$ ion fourligand coordination interface were obtained from Lu et al., ${ }^{17}$ who performed an MD study of the p53 core domain.

The model of the p53 tetramer was solvated and the system was thermalized after a short minimization. Owing to the size of the system, the system was equilibrated by applying restraints of $1000 \mathrm{~kJ} / \mathrm{mol} / \mathrm{nm}^{2}$ to the DNA and the tetramerization helices. Then, four independent unrestrained MD simulations were performed from the final structures of the restrained runs for a total length of approximately $100 \mathrm{~ns}$. All of the MD simulations 
a
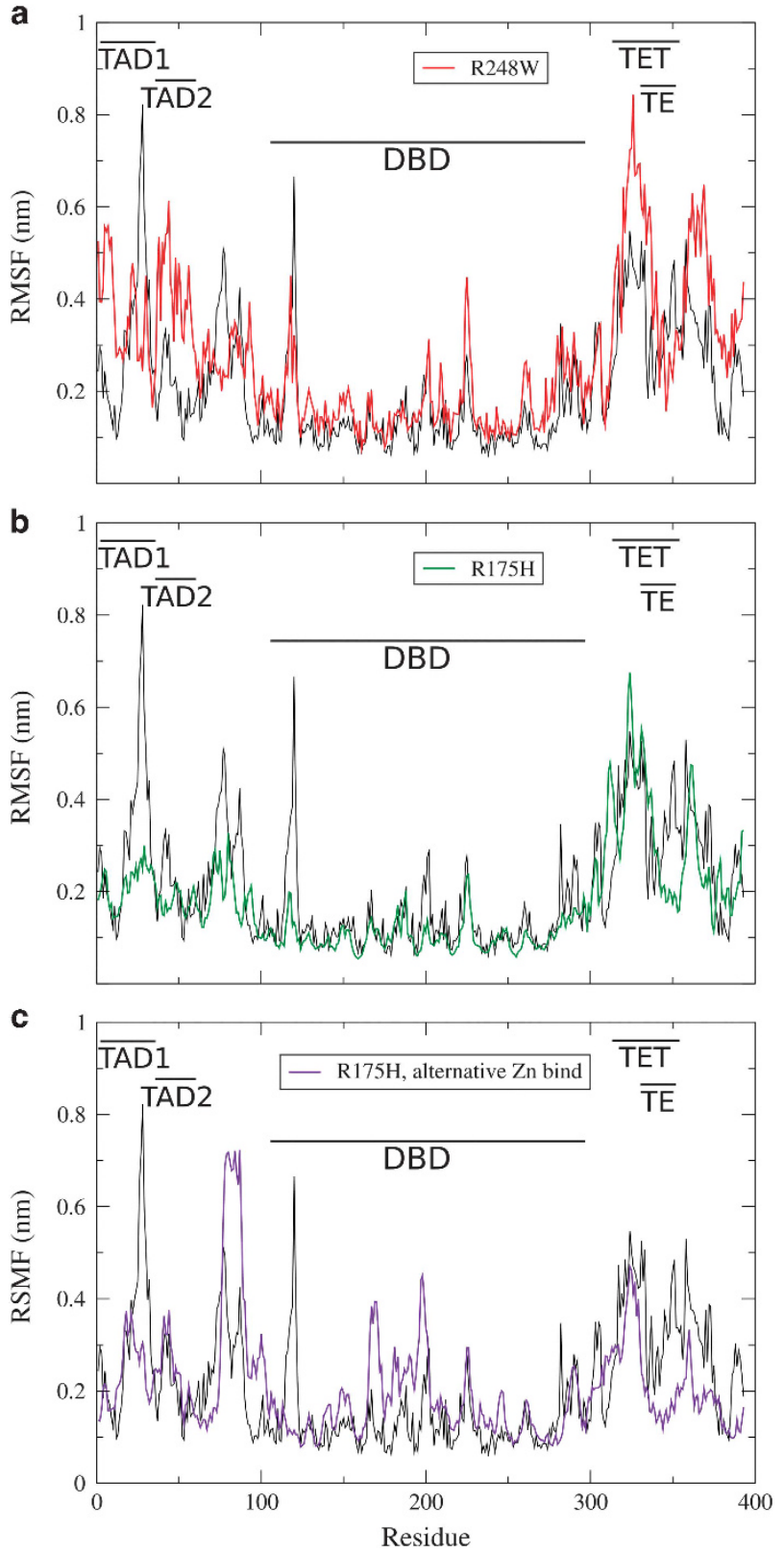

Figure 5. Per-residue root-mean-square fluctuations (RMSFs) for fulllength p53 in monomeric conformation. (a) RMSF for wild-type p53 and R248W mutant, the most common cancer mutation, are shown in black and red lines, respectively. The fluctuations in the mutant region are nearly identical to the wild-type protein, whereas strong perturbations are observed in the $\mathrm{N}$ - and $\mathrm{C}$-terminal domains. (b and c) RMSF for two alternative $\mathrm{Zn}$-binding models of $\mathrm{R} 175 \mathrm{H}$ mutant are shown in green and purple lines. Again, the greatest changes in fluctuation between mutants and wild-type protein are in the $\mathrm{N}$ - and $\mathrm{C}$-terminal domains.

were performed with the Gromacs 4.5 .6 package $^{116}$ and the amber99sb force field. ${ }^{17}$ The Particle-Mesh Ewald method was used for the treatment of the long-range electrostatic interactions. ${ }^{118}$ V-rescale temperature coupling was used to keep the temperature constant (298 K). The DCC $\mathrm{Map}^{18}$ of the p53 tetramer was built with the gromacs g_covar tool. The essential dynamics analysis ${ }^{19}$ was applied to the MD trajectory of the DBDs (residues 92-287), both in the tetramer (780 C-a carbons; $100 \mathrm{~ns} ; 100000$ frames) and on the concatenated trajectory (195 C-a carbons; 4x100 ns; 400000 frames), using the gromacs g_covar and g_anaeig tools. Perresidue RMSF, hydrogen bonds and secondary structure content were obtained with the gromacs tools g_rmsf, g_hbond and do_dssp, which is an interface to the DSSP program. ${ }^{119}$ The DNA parameters were obtained with the Curves+ program. ${ }^{28}$ The electrostatic potential was calculated with the APBS software using 2.0 and 80 as the solute and solvent dielectrics at zero salt concentration, respectively. ${ }^{120}$ The figures in the 3D structures were generated with vmd. ${ }^{121}$

Average properties such as DCC Map, per-residue RMSF and hydrogen bonds were checked against random time windows, each containing 25000 frames.

\section{CONFLICT OF INTEREST}

The authors declare no conflicts of interest.

\section{ACKNOWLEDGEMENTS}

This work was supported by a MIUR-FIRB grant (no. RBFR12BGHO) and 'Rita Levi Montalcini' research program. We acknowledge the Cineca Supercomputing centre for computational resources.

\section{REFERENCES}

1 Petitjean A, Mathe E, Kato S, Ishioka C, Tavtigian SV, Hainaut P et al. Impact of mutant p53 functional properties on TP53 mutation patterns and tumor phenotype: lessons from recent developments in the IARC TP53 database. Hum Mutat 2007; 28: 622-629.

2 Leroy B, Fournier JL, Ishioka C, Monti P, Inga A, Fronza G et al. The TP53 website: an integrative resource centre for the TP53 mutation database and TP53 mutant analysis. Nucleic Acids Res 2013; 41: D962-D969.

3 Yoshida K, Miki Y. The cell death machinery governed by the p53 tumor suppressor in response to DNA damage. Cancer Sci 2010; 101: 831-835.

4 Chari NS, Pinaire NL, Thorpe L, Medeiros LJ, Routbort MJ, McDonnell TJ. The p53 tumor suppressor network in cancer and the therapeutic modulation of cell death. Apoptosis 2009; 14: 336-347.

5 Giono LE, Manfredi JJ. The p53 tumor suppressor participates in multiple cell cycle checkpoints. J Cell Physiol 2006; 209: 13-20.

6 Feng H, Jenkins LMM, Durell SR, Hayashi R, Mazur SJ, Cherry S et al. Structural basis for p300 Taz2-p53 TAD1 binding and modulation by phosphorylation. Structure 2009; 17: 202-210.

7 Rowell JP, Simpson KL, Stott K, Watson M, Thomas JO. HMGB1-facilitated p53 DNA binding occurs via HMG-Box/p53 transactivation domain interaction, regulated by the acidic tail. Structure 2012; 20: 2014-2024.

8 Bochkareva E, Kaustov L, Ayed A, Yi G-S, Lu Y, Pineda-Lucena A et al. Singlestranded DNA mimicry in the p53 transactivation domain interaction with replication protein A. Proc Natl Acad Sci USA 2005; 102: 15412-15417.

9 Cho Y, Gorina S, Jeffrey PD, Pavletich NP. Crystal structure of a p53 tumor suppressorDNA complex: understanding tumorigenic mutations. Science 1994; 265: 346-355.

10 Jeffrey PD, Gorina S, Pavletich NP. Crystal structure of the tetramerization domain of the p53 tumor suppressor at 1.7 angstroms. Science 1995; 267: 1498-1502.

11 Cañadillas JMP, Tidow H, Freund SMV, Rutherford TJ, Ang HC, Fersht AR. Solution structure of p53 core domain: structural basis for its instability. Proc Natl Acad Sci USA 2006; 103: 2109-2114.

12 Tidow H, Melero R, Mylonas E, Freund SMV, Grossmann JG, Carazo JM et al. Quaternary structures of tumor suppressor p53 and a specific p53 DNA complex. Proc Natl Acad Sci USA 2007; 104: 12324-12329.

13 Chillemi G, Davidovich P, D’Abramo M, Mametnabiev T, Garabadzhiu AV, Desideri A et al. Molecular dynamics of the full-length p53 monomer. Cell Cycle 2013; 12: 3098-3108.

14 Lubin DJ, Butler JS, Loh SN. Folding of tetrameric p53: oligomerization and tumorigenic mutations induce misfolding and loss of function. $J \mathrm{Mol} \mathrm{Biol} 2010$; 395: 705-716.

15 Wassman CD, Baronio R, Demir Ö, Wallentine BD, Chen C-K, Hall LV et al. Computational identification of a transiently open $\mathrm{L} 1 / \mathrm{S} 3$ pocket for reactivation of mutant p53. Nat Commun 2013; 4: 1407.

16 Demir Ö, Baronio R, Salehi F, Wassman CD, Hall L, Hatfield GW et al. Ensemblebased computational approach discriminates functional activity of p53 cancer and rescue mutants. PLoS Comput Biol 2011; 7: e1002238.

$17 \mathrm{Lu} \mathrm{Q}$, Tan Y-H, Luo R. Molecular dynamics simulations of p53 DNAbinding domain. J Phys Chem B 2007; 111: 11538-11545.

18 McCammon JA, Harvey SC. Dynamics of Proteins and Nucleic Acids. Cambridge University Press: Cambridge, UK, 1988, pp 289-302.

19 Van Aalten DMF, de Groot BL, Findlay JBC, Berendsen HJC, Amadei A. A comparison of techniques for calculating protein essential dynamics. J Comput Chem 1997; 18: 169-181. 
20 Amadei A, Linssen ABM, Berendsen HJC. Essential dynamics of proteins. Proteins Struct Funct Genet 1993; 17: 412-425.

21 Kern D, Zuiderweg ERP. The role of dynamics in allosteric regulation. Curr Opin Struct Biol 2003; 13: 748-757.

22 Henzler-Wildman K, Kern D. Dynamic personalities of proteins. Nature 2007; 450: 964-972.

23 Lange OF, Grubmüller H. Full correlation analysis of conformational protein dynamics. Proteins Struct Funct Genet 2008; 70: 1294-1312.

24 Melero R, Rajagopalan S, Lázaro M, Joerger AC, Brandt T, Veprintsev DB et al. Electron microscopy studies on the quaternary structure of p53 reveal different binding modes for p53 tetramers in complex with DNA. Proc Natl Acad Sci USA 2011; 108: 557-562.

25 Chen Y, Dey R, Chen L. Crystal structure of the p53 core domain bound to a full consensus site as a self-assembled tetramer. Structure 2010; 18: 246-256.

26 Petty TJ, Emamzadah S, Costantino L, Petkova I, Stavridi ES, Saven JG et al. An induced fit mechanism regulates p53 DNA binding kinetics to confer sequence specificity. EMBO J 2011; 30: 2167-2176.

27 Pan Y, Nussinov R. Lysine120 interactions with p53 response elements can allosterically direct p53 organization. PLoS Comput Biol 2010; 6: 1-13.

28 Lavery R, Moakher M, Maddocks JH, Petkeviciute D, Zakrzewska K. Conformational analysis of nucleic acids revisited: Curves+. Nucleic Acids Res 2009; 37: 5917-5929.

29 Lu XJ, Olson WK. 3DNA: a software package for the analysis, rebuilding and visualization of three-dimensional nucleic acid structures. Nucleic Acids Res 2003; 31: 5108-5121.

30 Laptenko O, Shiff I, Freed-Pastor W, Zupnick A, Mattia M, Freulich E et al. The p53 $C$ terminus controls site-specific DNA binding and promotes structural changes within the central DNA binding domain. Mol Cell 2015; 57: 1034-1046.

31 Spolar RS, Record MT. Coupling of local folding to site-specific binding of proteins to DNA. Science 1994; 263: 777-784.

32 Jiang P, Du W, Mancuso A, Wellen KE, Yang X. Reciprocal regulation of p53 and malic enzymes modulates metabolism and senescence. Nature 2013; 493: 689-693.

33 Venkatanarayan A, Raulji P, Norton W, Chakravarti D, Coarfa C, Su X et al. IAPPdriven metabolic reprogramming induces regression of p53-deficient tumours in vivo. Nature 2014; 517: 626-630.

34 Méniel V, Megges M, Young MA, Cole A, Sansom OJ, Clarke AR. Apc and p53 interaction in DNA damage and genomic instability in hepatocytes. Oncogene 2014; 34: 4118-4129.

35 Van Nostrand JL, Brady Ca, Jung H, Fuentes DR, Kozak MM, Johnson TM et al. Inappropriate p53 activation during development induces features of CHARGE syndrome. Nature 2014; 514: 228-232.

36 Shetzer Y, Kagan S, Koifman G, Sarig R, Kogan-Sakin I, Charni M et al. The onset of p53 loss of heterozygosity is differentially induced in various stem cell types and may involve the loss of either allele. Cell Death Differ 2014; 21: 1419-1431.

37 Nair BC, Krishnan SR, Sareddy GR, Mann M, Xu B, Natarajan M et al. Proline, glutamic acid and leucine-rich protein-1 is essential for optimal p53-mediated DNA damage response. Cell Death Differ 2014; 21: 1409-1418.

38 Zhu L, Lu Z, Zhao H. Antitumor mechanisms when pRb and p53 are genetically inactivated. Oncogene 2014; 34: 4547-4557.

39 Merlo P, Frost B, Peng S, Yang YJ, Park PJ, Feany M. p53 prevents neurodegeneration by regulating synaptic genes. Proc Natl Acad Sci USA 2014; 111: 18055-18060

40 Dudgeon C, Chan C, Kang W, Sun Y, Emerson R, Robins $\mathrm{H}$ et al. The evolution of thymic lymphomas in p53 knockout mice. Genes Dev 2014; 28: 2613-2620.

41 Tan EH, Morton JP, Timpson P, Tucci P, Melino G, Flores ER et al. Functions of TAp63 and p53 in restraining the development of metastatic cancer. Oncogene 2014; 33: 3325-3333.

42 Li T, Kon N, Jiang L, Tan M, Ludwig T, Zhao $Y$ et al. Tumor suppression in the absence of p53-mediated cell-cycle arrest, apoptosis, and senescence. Cell 2012; 149: 1269-1283.

43 Antonov AV, Krestyaninova M, Knight RA, Rodchenkov I, Melino G, Barlev NA. PPISURV: a novel bioinformatics tool for uncovering the hidden role of specific genes in cancer survival outcome. Oncogene 2014; 33: 1621-1628.

44 Kim J, Nakasaki M, Todorova D, Lake B, Yuan C-Y, Jamora C et al. P53 induces skin aging by depleting Blimp1(+) sebaceous gland cells. Cell Death Dis 2014; 5: e1141.

45 Fatt MP, Cancino Gl, Miller FD, Kaplan DR. P63 and P73 coordinate P53 function to determine the balance between survival, cell death, and senescence in adult neural precursor cells. Cell Death Differ 2014; 21: 1546-1559.

46 Rufini A, Tucci P, Celardo I, Melino G. Senescence and aging: the critical roles of p53. Oncogene 2013; 32: 5129-5143.

47 Levine AJ, Tomasini R, McKeon FD, Mak TW, Melino G. The p53 family: guardians of maternal reproduction. Nat Rev Mol Cell Biol 2011; 12: 259-265.

48 Müller M, Schleithoff ES, Stremmel W, Melino G, Krammer PH, Schilling T. One, two, three-p53, p63, p73 and chemosensitivity. Drug Resist Updat 2006; 9: 288-306.
49 Tomasini R, Mak TW, Melino G. The impact of p53 and p73 on aneuploidy and cancer. Trends Cell Biol 2008; 18: 244-252.

50 Tschaharganeh DF, Xue W, Calvisi DF, Evert M, Michurina TV, Dow LE et al. P53dependent nestin regulation links tumor suppression to cellular plasticity in liver cancer. Cell 2014; 158: 579-592.

51 Weissmueller S, Manchado E, Saborowski M, Morris JP, Wagenblast E, Davis CA et al. Mutant p53 drives pancreatic cancer metastasis through cell-autonomous PDGF receptor $\beta$ signaling. Cell 2014; 157: 382-394.

52 Lujambio A, Akkari L, Simon J, Grace D, Tschaharganeh DF, Bolden JE et al. Noncell-autonomous tumor suppression by p53. Cell 2013; 153: 449-460.

53 Buckley NE, D'Costa Z, Kaminska M, Mullan PB. S100A2 is a BRCA1/p63 coregulated tumour suppressor gene with roles in the regulation of mutant p53 stability. Cell Death Dis 2014; 5: e1070.

54 Xu J, Wang J, Hu Y, Qian J, Xu B, Chen H et al. Unequal prognostic potentials of p53 gain-of-function mutations in human cancers associate with drugmetabolizing activity. Cell Death Dis 2014; 5: e1108.

55 Foijer F, Xie SZ, Simon JE, Bakker PL, Conte N, Davis SH et al. Chromosome instability induced by $M p s 1$ and p53 mutation generates aggressive lymphomas exhibiting aneuploidy-induced stress. Proc Natl Acad Sci USA 2014; 111: 13427-13432.

56 Mello SS, Attardi LD. Not all p53 gain-of-function mutants are created equal. Cell Death Differ 2013; 20: 855-857.

57 Vaseva AV, Marchenko ND, Ji K, Tsirka SE, Holzmann S, Moll UM. P53 opens the mitochondrial permeability transition pore to trigger necrosis. Cell 2012; 149: 1536-1548.

58 Maddocks ODK, Berkers CR, Mason SM, Zheng L, Blyth K, Gottlieb E et al. Serine starvation induces stress and p53-dependent metabolic remodelling in cancer cells. Nature 2013; 493: 542-546.

59 Amelio I, Markert EK, Rufini A, Antonov AV, Sayan BS, Tucci P et al. P73 regulates serine biosynthesis in cancer. Oncogene 2013; 33: 5039-5046.

60 Evstafieva AG, Garaeva AA, Khutornenko AA, Klepikova AV, Logacheva MD, Penin AA et al. A sustained deficiency of mitochondrial respiratory complex III induces an apoptotic cell death through the p53-mediated inhibition of pro-survival activities of the activating transcription factor 4. Cell Death Dis 2014; 5: e1511.

61 Peuget S, Bonacci T, Soubeyran P, lovanna J, Dusetti NJ. Oxidative stress-induced p53 activity is enhanced by a redox-sensitive TP53INP1 SUMOylation. Cell Death Differ 2014; 21: 1107-1118.

62 Shi Y, Nikulenkov F, Zawacka-Pankau J, Li H, Gabdoulline R, Xu J et al. ROSdependent activation of JNK converts p53 into an efficient inhibitor of oncogenes leading to robust apoptosis. Cell Death Differ 2014; 21: 612-623.

63 Rufini A, Niklison-Chirou MV, Inoue S, Tomasini R, Harris IS, Marino A et al. TAp73 depletion accelerates aging through metabolic dysregulation. Genes Dev 2012; 26: 2009-2014.

64 Drosten M, Sum EYM, Lechuga CG, Simón-Carrasco L, Jacob HKC, García-Medina R et al. Loss of p53 induces cell proliferation via Ras-independent activation of the Raf/Mek/Erk signaling pathway. Proc Natl Acad Sci USA 2014; 111: 15155-15160.

65 Zhang H-H, Li S-Z, Zhang Z-Y, Hu X-M, Hou P-N, Gao L et al. Nemo-like kinase is criticalor p53 stabilization and function in response to DNA damage. Cell Death Differ 2014; 21: 1656-1663.

66 Tang Z, Chen W-Y, Shimada M, Nguyen UTT, Kim J, Sun X-J et al. SET1 and p300 act synergistically, through coupled histone modifications, in transcriptional activation by p53. Cell 2013; 154: 297-310.

67 Dashzeveg N, Taira N, Lu Z-G, Kimura J, Yoshida K. Palmdelphin, a novel target of p53 with Ser46 phosphorylation, controls cell death in response to DNA damage. Cell Death Dis 2014; 5: e1221.

68 Li D, Yallowitz A, Ozog L, Marchenko N. A gain-of-function mutant p53-HSF1 feed forward circuit governs adaptation of cancer cells to proteotoxic stress. Cell Death Dis 2014; 5: e1194.

69 Manzl C, Fava LL, Krumschnabel G, Peintner L, Tanzer MC, Soratroi C et al. Death of p53-defective cells triggered by forced mitotic entry in the presence of DNA damage is not uniquely dependent on caspase-2 or the PIDDosome. Cell Death Dis 2013; 4: e942.

70 Phesse TJ, Myant KB, Cole AM, Ridgway RA, Pearson H, Muncan V et al. Endogenous c-Myc is essential for p53-induced apoptosis in response to DNA damage in vivo. Cell Death Differ 2014; 21: 956-966.

71 Gorrini C. Discovery of a p53 variant that controls metastasis. Proc Natl Acad Sci USA 2014; 111: 11576-11577.

72 Senturk S, Yao Z, Camiolo M, Stiles B, Rathod T, Walsh AM et al. P53\% is a transcriptionally inactive P53 isoform able to reprogram cells toward a metastatic-like state. Proc Natl Acad Sci USA 2014; 111: E3287-E3296.

73 Solomon $\mathrm{H}$, Sharon M, Rotter V. Modulation of alternative splicing contributes to cancer development: focusing on $\mathrm{p} 53$ isoforms, $\mathrm{p} 53 \beta$ and $\mathrm{p} 53 \gamma$. Cell Death Differ 2014; 21: 1347-1349.

74 Marcel V, Fernandes K, Terrier O, Lane DP, Bourdon J-C. Modulation of p53 3 and p53y expression by regulating the alternative splicing of TP53 gene modifies cellular response. Cell Death Differ 2014; 21: 1377-1387. 
75 Hoffman Y, Bublik DR, Pilpel Y, Oren M. miR-661 downregulates both Mdm2 and Mdm4 to activate p53. Cell Death Differ 2014; 21: 302-309.

76 Balatti V, Rizzotto L, Miller C, Palamarchuk A, Fadda P, Pandolfo R et al. TCL1 targeting miR-3676 is codeleted with tumor protein p53 in chronic lymphocytic leukemia. Proc Natl Acad Sci USA 2015; 112: 2169-2174.

77 Fiori ME, Barbini C, Haas TL, Marroncelli N, Patrizii M, Biffoni M et al. Antitumor effect of miR-197 targeting in p53 wild-type lung cancer. Cell Death Differ 2014; 21: 774-782.

78 Okada N, Lin CP, Ribeiro MC, Biton A, Lai G, He X et al. A positive feedback between p53 and miR-34 miRNAs mediates tumor suppression. Genes Dev 2014; 28: $438-450$

79 Burns DM, D'Ambrogio A, Nottrott S, Richter JD. CPEB and two poly(A) polymerases control miR-122 stability and p53 mRNA translation. Nature 2011; 473: 105-108.

80 Fortunato O, Boeri M, Moro M, Verri C, Mensah M, Conte D et al. Mir-660 is downregulated in lung cancer patients and its replacement inhibits lung tumorigenesis by targeting MDM2-p53 interaction. Cell Death Dis 2014; 5: e1564.

81 Lezina L, Purmessur N, Antonov AV, Ivanova T, Karpova E, Krishan K et al. miR-16 and miR-26a target checkpoint kinases Wee1 and Chk1 in response to p53 activation by genotoxic stress. Cell Death Dis 2013; 4: e953.

82 Tucci P, Agostini M, Grespi F, Markert EK, Terrinoni A, Vousden KH et al. Loss of p63 and its microRNA-205 target results in enhanced cell migration and metastasis in prostate cancer. Proc Natl Acad Sci USA 2012; 109: 15312-15317.

83 Zhang E, Yin D, Sun M, Kong R, Liu X, You L et al. P53-regulated long non-coding RNA TUG1 affects cell proliferation in human non-small cell lung cancer, partly through epigenetically regulating HOXB7 expression. Cell Death Dis 2014; 5: e1243.

84 Ren Z-J, Nong X-Y, Lv Y-R, Sun H-H, An P-P, Wang F et al. Mir-509-5p joins the $\mathrm{Mdm} 2 / \mathrm{p} 53$ feedback loop and regulates cancer cell growth. Cell Death Dis 2014; 5: e1387.

85 Gomes LR, Vessoni AT, Menck CFM. Three-dimensional microenvironment confers enhanced sensitivity to doxorubicin by reducing p53-dependent induction of autophagy. Oncogene 2015; 34: 5329-5340.

86 Simon HU, Yousefi S, Schmid I, Friis R. ATG5 can regulate p53 expression and activation. Cell Death Dis 2014; 5: e1339.

87 He Z, Liu H, Agostini M, Yousefi S, Perren A, Tschan MP et al. P73 regulates autophagy and hepatocellular lipid metabolism through a transcriptional activation of the ATG5 gene. Cell Death Differ 2013; 20: 1415-1424.

88 Garufi A, Pucci D, D’Orazi V, Cirone M, Bossi G, Avantaggiati ML et al. Degradation of mutant p53H175 protein by $\mathrm{Zn}(\mathrm{II})$ through autophagy. Cell Death Dis 2014; 5: e1271.

$89 \mathrm{Ci} \mathrm{Y,} \mathrm{Shi} \mathrm{K,} \mathrm{An} \mathrm{J,} \mathrm{Yang} \mathrm{Y,} \mathrm{Hui} \mathrm{K,} \mathrm{Wu} \mathrm{P} \mathrm{et} \mathrm{al.} \mathrm{ROS} \mathrm{inhibit} \mathrm{autophagy} \mathrm{by} \mathrm{down-}$ regulating ULK1 mediated by the phosphorylation of $\mathrm{p} 53$ in selenite-treated NB4 cells. Cell Death Dis 2014; 5: e1542.

90 Rossi M, Rotblat B, Ansell K, Amelio I, Caraglia M, Misso G et al. High throughput screening for inhibitors of the HECT ubiquitin E3 ligase ITCH identifies antidepressant drugs as regulators of autophagy. Cell Death Dis 2014; 5: e1203.

91 Pant V, Lozano G. Limiting the power of p53 through the ubiquitin proteasome pathway. Genes Dev 2014; 28: 1739-1751.

92 Emerling BM, Hurov JB, Poulogiannis G, Tsukazawa KS, Choo-Wing R, Wulf GM et al. XDepletion of a putatively druggable class of phosphatidylinositol kinases inhibits growth of p53-Null tumors. Cell 2013; 155: 844-857.

93 Weilbacher A, Gutekunst M, Oren M, Aulitzky WE, van der Kuip H. RITA can induce cell death in p53-defective cells independently of p53 function via activation of JNK/SAPK and p38. Cell Death Dis 2014; 5: e1318.

94 Li H, Zhang Y, Ströse A, Tedesco D, Gurova K, Selivanova G. Integrated highthroughput analysis identifies Sp1 as a crucial determinant of p53-mediated apoptosis. Cell Death Differ 2014; 21: 1522-1534.

95 Kelly GL, Grabow S, Glaser SP, Fitzsimmons L, Aubrey BJ, Okamoto T et al. Targeting of MCL-1 kills MYC-driven mouse and human lymphomas even when they bear mutations in p53. Genes Dev 2014; 28: 58-70.

96 Malatesta M, Peschiaroli A, Memmi EM, Zhang J, Antonov A, Green DR et al. The Cul4A-DDB1 E3 ubiquitin ligase complex represses p73 transcriptional activity. Oncogene 2012; 32: 4721-4726.

97 Fan Y-H, Cheng J, Vasudevan Sa, Dou J, Zhang H, Patel RH et al. USP7 inhibitor P22077 inhibits neuroblastoma growth via inducing p53-mediated apoptosis. Cell Death Dis 2013; 4: e867.

98 Zaccara S, Tebaldi T, Pederiva C, Ciribilli Y, Bisio A, Inga A. P53-directed translational control can shape and expand the universe of P53 target genes. Cell Death Differ 2014; 21: 1522-1534
99 Brune M, Müller M, Melino G, Bierhaus A, Schilling T, Nawroth PP. Depletion of the receptor for advanced glycation end products (RAGE) sensitizes towards apoptosis via p53 and p73 posttranslational regulation. Oncogene 2012; 32: 1460-1468.

100 Han F, Liu W, Jiang X, Shi X, Yin L, Ao L et al. SOX30, a novel epigenetic silenced tumor suppressor, promotes tumor cell apoptosis by transcriptional activating p53 in lung cancer. Oncogene 2014; 34: 4391-4402.

101 Link N, Kurtz P, O’Neal M, Garcia-Hughes G, Abrams JM. A p53 enhancer region regulates target genes through chromatin conformations in cis and in trans. Genes Dev 2013; 27: 2433-2438.

102 Saldaña-Meyer R, González-Buendía E, Guerrero G, Narendra V, Bonasio R, Recillas-Targa $F$ et al. CTCF regulates the human p53 gene through direct interaction with its natural antisense transcript, Wrap53. Genes Dev 2014; 28: 723-734.

103 Terrinoni A, Pagani IS, Zucchi I, Chiaravalli AM, Serra V, Rovera F et al. OTX1 expression in breast cancer is regulated by p53. Oncogene 2011; 30: 3096-3103.

104 Zambetti GP. Expanding the reach of the p53 tumor suppressor network. Cell Death Differ 2014; 21: 505-506.

105 Wang G, Fersht AR. Propagation of aggregated p53: cross-reaction and coaggregation vs. seeding. Proc Natl Acad Sci USA 2015; 112: 2443-2448.

106 Wang G, Fersht AR. Mechanism of initiation of aggregation of p53 revealed by $\phi$-value analysis. Proc Natl Acad Sci USA 2015; 112: 2437-2442.

107 Yang-Hartwich Y, Soteras MG, Lin ZP, Holmberg J, Sumi N, Craveiro V et al. P53 protein aggregation promotes platinum resistance in ovarian cancer. Oncogene 2014; 34: 3605-3616.

108 Chuikov S, Kurash JK, Wilson JR, Xiao B, Justin N, Ivanov GS et al. Regulation of p53 activity through lysine methylation. Nature 2004; 432: 353-360.

109 Carr SM, Munro S, La Thangue NB. Lysine methylation and the regulation of $\mathrm{p} 53$. Essays Biochem 2012; 52: 79-92.

110 Koshland DE. Application of a Theory of Enzyme Specificity to Protein Synthesis. Proc Natl Acad Sci USA 1958; 44: 98-104.

111 Johnson KA. Role of induced fit in enzyme specificity: a molecular forward/ reverse switch. J Biol Chem 2008; 283: 26297-26301.

112 Emamzadah S, Tropia L, Vincenti I, Falquet B, Halazonetis TD. Reversal of the DNA-binding-induced loop L1 conformational switch in an engineered human p53 protein. J Mol Biol 2014; 426: 936-944.

113 Oldfield CJ, Meng J, Yang JY, Yang MQ, Uversky VN, Dunker AK. Flexible nets: disorder and induced fit in the associations of p53 and 14-3-3 with their partners. BMC Genomics 2008; 9: S1.

114 Sali A, Blundell TL. Comparative protein modelling by satisfaction of spatial restraints. J Mol Biol 1993; 234: 779-815.

115 Kuszewski J, Gronenborn AM, Clore GM. Improving the packing and accuracy of NMR structures with a pseudopotential for the radius of gyration. J Am Chem Soc 1999; 121: 2337-2338.

116 Pronk S, Páll S, Schulz R, Larsson P, Bjelkmar P, Apostolov R et al. GROMACS 4.5: a high-throughput and highly parallel open source molecular simulation toolkit. Bioinformatics 2013; 29: 845-854.

117 Hornak V, Abel R, Okur A, Strockbine B, Roitberg A, Simmerling C. Comparison of multiple amber force fields and development of improved protein backbone parameters. Proteins Struct Funct Genet 2006; 65: 712-725.

118 Darden T, York D, Pedersen L. Particle mesh Ewald: an $N \log (\mathrm{N})$ method for Ewald sums in large systems. J Chem Phys 1993; 98: 10089.

119 Kabsch W, Sander C. Dictionary of protein secondary structure: pattern recognition of hydrogen-bonded and geometrical features. Biopolymers 1983; 22: 2577-2637.

120 Baker NA, Sept D, Joseph S, Holst MJ, McCammon JA. Electrostatics of nanosystems: application to microtubules and the ribosome. Proc Natl Acad Sci USA 2001; 98: 10037-10041.

121 Humphrey W, Dalke A, Schulten K. VMD: visual molecular dynamics. J Mol Graph 1996; 14: 33-38.

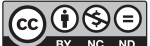

This work is licensed under a Creative Commons AttributionNonCommercial-NoDerivs 4.0 International License. The images or other third party material in this article are included in the article's Creative Commons license, unless indicated otherwise in the credit line; if the material is not included under the Creative Commons license, users will need to obtain permission from the license holder to reproduce the material. To view a copy of this license, visit http:// creativecommons.org/licenses/by-nc-nd/4.0/ 